\begin{tabular}{cc}
\hline & International Journal of Engineering \&Technology, $7(3.12)(2018) 322-325$ \\
SPC & Website: ww.sciencepubco.com/index.php/IJET \\
Research paper & Technology \\
\hline
\end{tabular}

\title{
Troubled Projects in Construction Due To Scant Risk Management
}

\author{
Subramanyam $\mathbf{B}^{1}$, Iswarya $\mathbf{R}^{2}$ \\ ${ }^{1}$ School of Civil Engineering, SASTRA Deemed University, Thanjavur, India \\ ${ }^{2}$ M.Tech, .School of Civil Engineering, SASTRA Deemed University, Thanjavur, India \\ *Corresponding Author Email: ${ }^{1}$ subramanyam@civil.sastra.edu
}

\begin{abstract}
This paper will focus on troubled projects in construction due to inadequate and insufficient risk management. Inadequate risk management has the ability to severely impact construction project. The main objective of the present paper is to attempt a composition of already known risk management process, at such way that it can be applied by the modern enterprises that deal with the undertaking or/and implementation of constructional work. This paper describes about the main sources for the failure of a construction project such as no initial risk assessment, inadequate documentation and tracking, irregular \& incomplete status reporting, failure to define parameters etc. The methodology contains examining existing data, results and created a checklist for all those who are involved in construction project disasters. It can be applied at all stages in the project cycle, from the earliest assessments of strategy to initiation, planning, implementation and closure. Risk management will also provide advantages in better accountability and justification of decisions, by providing a well-suited and robust process that supports decision-making.
\end{abstract}

Keywords: Risk, Management, Assessment, Project Cycle, Decision Making.

\section{Introduction}

Risk management is the process of forecasting and evaluation of financial risks together by identifying the measures to solve or minimize impacts. The risk includes poor user adoption, unrealized benefits, late-running projects, overspent budgets, unhappy clients, reputational damage, project failure etc.(Mohammed et al.,2016). To manage a particular project, the risk management team should have the knowledge of modern management as well as understanding of the design and construction process. Construction projects have specific set of objectives and constraints such as scope, cost and schedule (Alfredo et al.,2015). These constraints are also called as triple constraint or project management triangle. Design changes and rework are inevitable in a construction project. Change cannot be eliminated but by relating the principles of risk management, the project team is able to expand the effective management of this change (LI Qing et al.,2014).

The purpose of this study is to expose why the construction projects fail due to scant risk management and to suggest the best practices for the recovery. It also defines the pre-signals for the failure of the project, because of deficient risk management and the lack of rescue planning. It undertakes the importance of combining risk management planning into a construction project(Andreas et al.,2017). It can be applied at all stages in the project cycle, from the earliest assessments of strategy to initiation, planning, implementation and closure. In most conditions, projects have clear objectives with understandable vision and specification of their goals. Together this project is the lead to increase the certainty and to completely eliminate the overall risk exposure.

The main aim of the project is to eliminate the inadequacy in risk analysis or management which results most construction companies failing to plan for troubled projects. Thus by facilitating improved business and project outcomes by providing insight, knowledge, ideas and confidence for better decisionmaking(Xiaohua et al.,2017).

If the risk management is ignored then the following troubles may occur

- Contractual problems

- Quality concerns

- Delays

- Increased costs

- Profit reduction

- Damage to the brand/reputation

- Insolvency

Therefore efficient risk management is mandatory for the successful completion of any construction project.

The various objectives of this project include:

- Collection of data

- Defining the procedure

- Performing analysis

- Revise the analysis

- Draw consequences

- Preparation of report

- Follow-up

The flow chart which represents the various objectives of the project is represented in figure 1. 


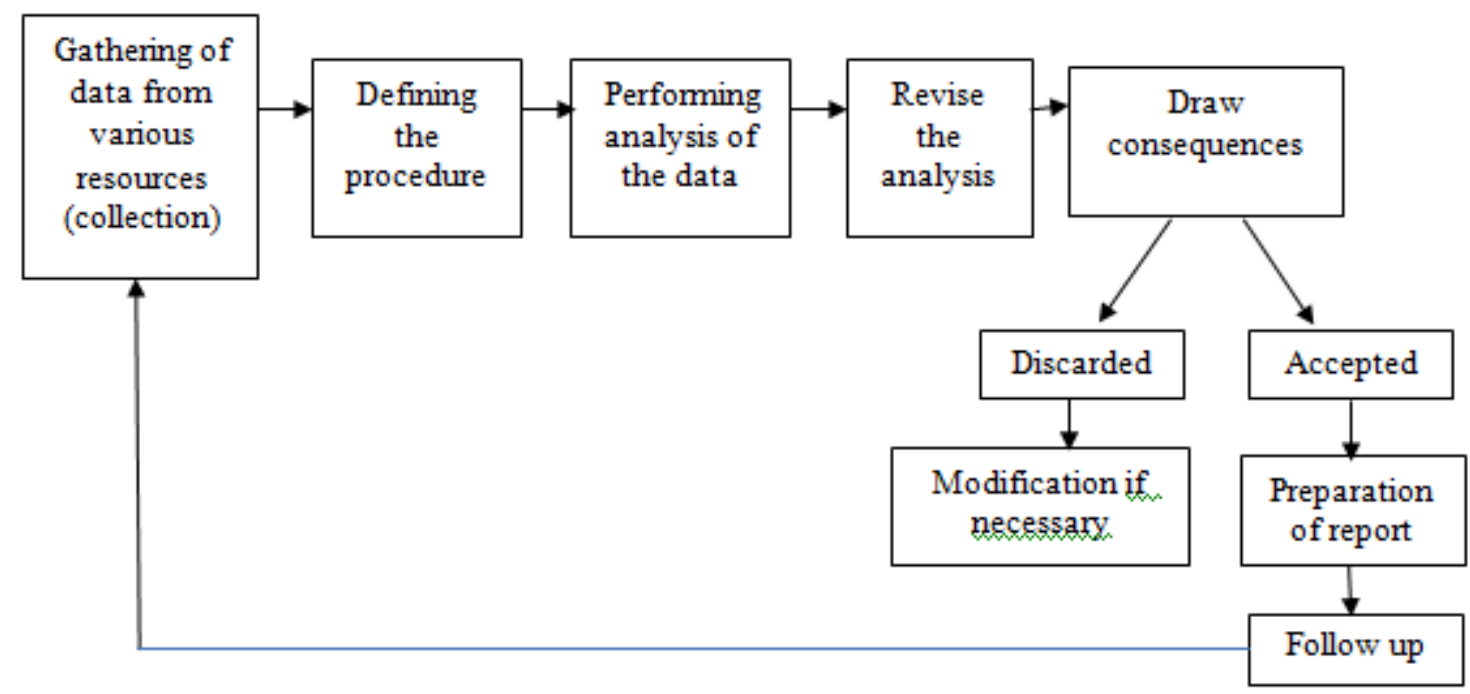

Fig. 1: Flow Chart for Objectives

\section{Methodology}

The main sources of data which is given as input in this research are gathered from various literatures and a questionnaire survey which contains list of questions regarding the risk management is conducted to a group of qualified personnel in a construction industry. The Data which is gathered from various construction industries via the questionnaire survey is then evaluated by means of statistical analysis. The findings which are obtained from the statistical analysis will be given as input to spreadsheet file which is developed to assist each personnel working in the construction industry which helps them in attaining the efficient risk management process for their upcoming projects.
The Questionnaire consists of set of printed questions with different options of answers (Pawelszymanski, 2017). This was further studied with experimental survey for transparency, usability and importance of information. The survey is broadly classified into three sections. The first section deals with the organization profile, the second section deals with the various risk factors and the third section deals with the handling risks and declaration. About 28 risk factors in 9 different categories are given based upon the experimental study.

Special software SPSS stands for Statistical Package for Social Science is used for performing the statistical operations of the data gathered. Now the current versions of this software are named as IBM SPSS. In this thesis statistical analysis are performed using IBM SPSS version 14. Theflow chartas shown in figure 2, represents methodology.

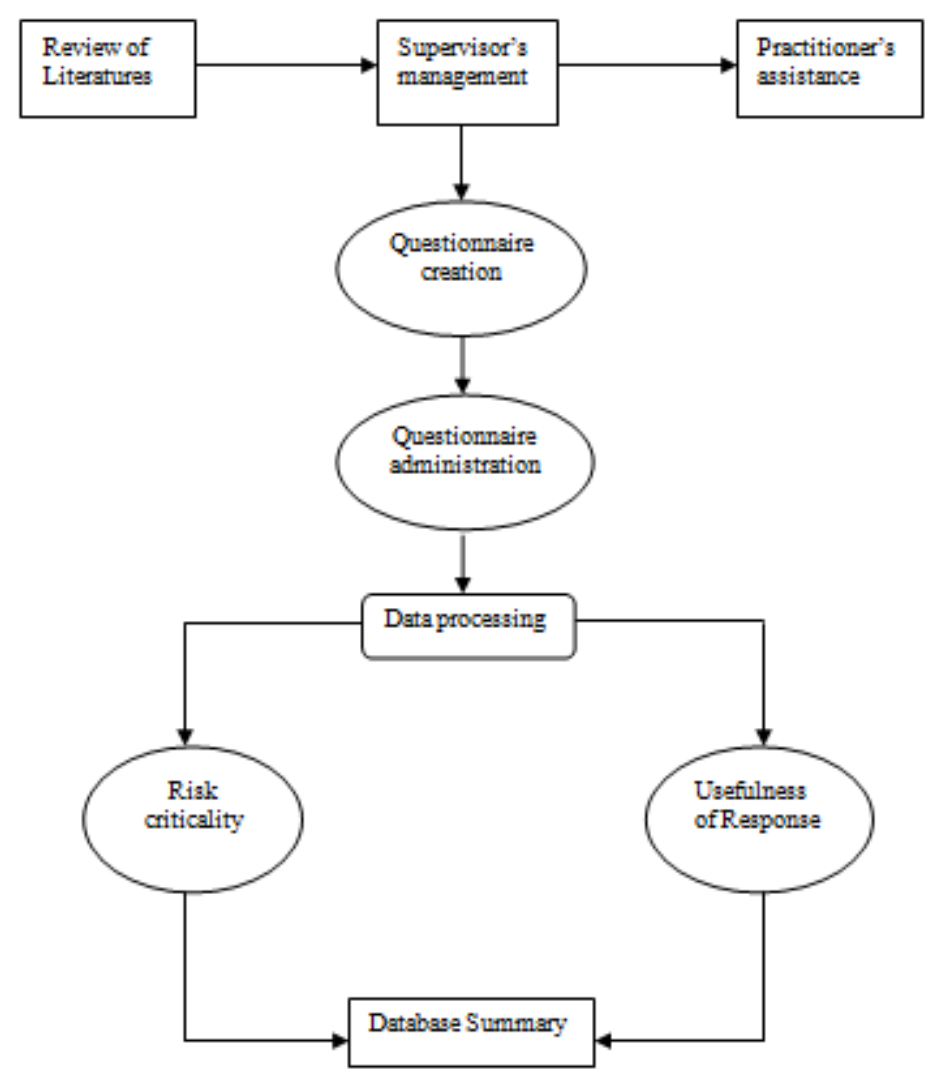

Fig. 2: Flow chart for Methodology 


\section{Results and Discussions}

The data obtained is analyzed with the Statistical Package for the Social and Science (SPSS). SPSS is used extensively in business, government and academia. It is a statistical analysis package and so allows any organization or individual that holds large amounts of data to analyze it and understand it more deeply. At its most simple it is very useful for discovering correlations between different variables. At its most powerful it can be used to make statistically valid forecasts for future events or results. To identify the factors that influences the sustainable practice in their project construction at urban level. Table1 shows the reliability of collected data to further analysis to find the risk of the project(Adam and Göran, 2015, Mohamed et al.,2017).

The results presented in Table 2 shows the factors (like physical risk, environmental risk, design risk, Logistics risks etc.,) and their relationship between them that could influence the dependent variable. The local firm's management system should adopt various available features in the industry to obtain the sustainable practices in construction. Environmental Management System (EMS) which refers to the management of an organization's environmental programs in a comprehensive, systematic, planned and documented manner. It includes the organizational structure, planning and resources for developing, implementing and maintaining policy for environmental protection. Environmental Impact Assessment (EIA) EIA is a universally accepted observable fact for setting off impacts of a project at its preliminary phase and can be valuable to a multitude of industries, utilities, infrastructure projects, institutions, technology transfer projects, policy makers etc. Different types of Impact Assessment risk are as listed below, though they are not limited to: Physical risks, Environmental risks, Design risks, Logistics risks, Financial risks, Legal risks, Construction risks, Political risks and Management risks (Agnieszka and Mariusz, 2015, Alfredo et al.,2014). The variables are used to formulate hypotheses concerning their impact upon the structuring of construction projects and these are studied. Based on the case studies, by involving, these methods for obtaining a feasible report on both sides of the practices. As the presence of the ability in following the better approach towards the sustainability the firm's management can involve own approaches in their projects. Thus involving of these methods can provide a support for the management to implement the practices in their projects.

Table 1: Reliability Test and Validity Test Analysis

\begin{tabular}{|c|c|c|c|}
\hline Risk Factors & $\mathbf{N}$ & Mean & Standard Deviation \\
\hline Occurrence of Accidents & 33 & 1.1212 & .33143 \\
\hline Supplies of Defective Materials & 33 & 1.6364 & .69903 \\
\hline Labor and Equipment Low Productivity & 33 & 1.6970 & .72822 \\
\hline Difficulty to Access the Site & 33 & 1.4242 & .50189 \\
\hline Unexpected Severe Weather Condition & 33 & 1.5758 & .56071 \\
\hline Occurrence of Natural Hazards & 33 & 1.2727 & .45227 \\
\hline Defective Design & 33 & 1.2727 & .57406 \\
\hline Lack of Consistency in Schedule & 33 & 1.5455 & .56408 \\
\hline Labor Material and Equipment & 33 & 2.0606 & .49620 \\
\hline Scope of Work defining & 33 & 2.1212 & .59987 \\
\hline Accuracy of Project Plan & 33 & 2.3333 & .59512 \\
\hline Changes in Prices & 33 & 2.2727 & .76128 \\
\hline Late Payment to Contractor & 33 & 2.0303 & .72822 \\
\hline Financial Failure & 33 & 1.9697 & .98377 \\
\hline Demonitarization & 33 & 2.0606 & .74747 \\
\hline Labor Strikes & 33 & 1.5455 & .61699 \\
\hline Third party Delays & 33 & 2.3030 & .76994 \\
\hline Delays in Resolving Disputes & 33 & 1.9697 & .76994 \\
\hline Change Order Negotiations & 33 & 2.0000 & .70711 \\
\hline Changes in work & 33 & 2.0606 & .65857 \\
\hline Government Acts & 33 & 2.2727 & .87581 \\
\hline Legislations & 33 & 2.1515 & .83371 \\
\hline Project Complexity & 33 & 1.5455 & .66572 \\
\hline Coordination with Sub Contractors & 33 & 2.0000 & .70711 \\
\hline Resource Management & 33 & 1.7879 & .73983 \\
\hline Communication & 33 & 1.8788 & .78093 \\
\hline
\end{tabular}

Table 2: Friedman Analysis

Physical Risks

\begin{tabular}{|c|c|c|c|}
\hline Rank & Name & Mean Rank & 1.53 \\
\hline 1 & Occurrence of Accidents & 2.23 & .32280 \\
\hline 2 & Supplies of Defective Materials & .69452 & 2.24 \\
\hline
\end{tabular}

Environmental Risks

\begin{tabular}{|c|c|c|c|}
\hline \multicolumn{4}{|c|}{ Environmental Risks } \\
\hline Rank & Name & Mean Rank & Standard Deviation \\
\hline 1 & Difficulty to Access the Site & 2.00 & .49705 \\
\hline 2 & Unexpected Severe Weather Condition & 2.20 & .56061 \\
\hline 3 & Occurrence of Natural Hazards & 1.80 & .44344 \\
\hline
\end{tabular}

Design Risks

\begin{tabular}{|c|c|c|c|}
\hline Rank & Name & Mean Rank & 1.89 \\
\hline 1 & Defective Design & 1.89 & .56061 \\
\hline 2 & Inaccuracy in Quantity Calculations & .56061 & 1.89 \\
\hline
\end{tabular}


Logistics Risks

\begin{tabular}{|c|c|c|c|}
\hline Rank & Name & Mean Rank & 1.87 \\
\hline 1 & Labor Material and Equipment & 1.97 & .52979 \\
\hline 2 & Scope of Work defining & .61767 & 2.16 \\
\hline
\end{tabular}

Financial Risks

\begin{tabular}{|c|c|c|c|}
\hline Rank & Name & Mean Rank & 2.87 \\
\hline 1 & Changes in Prices & 2.41 & .75111 \\
\hline 2 & Late Payment to Contractor & 2.32 & .73855 \\
\hline 3 & Financial Failure & 2.40 & .98292 \\
\hline
\end{tabular}

Legal Risks

\begin{tabular}{|c|c|c|c|}
\hline Rank & Name & Mean Rank & Standard Deviation \\
\hline 1 & Permits and Regulations & 2.80 & .80961 \\
\hline 2 & Labor Strikes & .61220 & 3 \\
\hline 3 & Third party Delays & 3.03 & .75035 \\
\hline 4 & Delays in Resolving Disputes & 2.44 \\
\hline
\end{tabular}

Construction Risks

\begin{tabular}{|c|c|c|c|}
\hline & Rank & Name & Mean Rank \\
\hline 1 & Change Order Negotiations & 1.47 \\
\hline 2 & Changes in work & .68599 & 1.53 \\
\hline
\end{tabular}

Political Risks

\begin{tabular}{|c|c|c|c|}
\hline Rank & Name & Mean Rank & Standard Deviation \\
\hline 1 & Government Acts & 1.54 & .88593 \\
\hline 2 & Legislations & 1.46 & .83314 \\
\hline
\end{tabular}

\begin{tabular}{|c|c|c|c|}
\multicolumn{3}{|c|}{ Management Risks } & Mean Rank \\
\hline Rank & Name & 2.10 & Standard Deviation \\
\hline 1 & Project Complexity & 3.00 & .66017 \\
\hline 2 & Coordination with Sub Contractors & 2.40 & .71712 \\
\hline 4 & Resource Management & 2.50 & .72944 \\
\hline
\end{tabular}

\section{Conclusion}

Risk management in construction field is a significant part in making decisions. A well planned risk management inspires the construction companies to categorize, measure and to study risk control and risk reduction policies. The construction companies which manage the risks effectively gains business savings, productivity, increased success rates of several new projects and healthier decision making. This paper governs the key factors of risk in construction industry. A total of 28 risk factors are analyzed through the experimental survey. Thus the research results show that the approach of risk management provides a most efficient, accurate \& structured decision support tool and also the risk management structure can be improved further by means of qualitative and quantitative methodologies.

\section{References}

[1] Mohammed Algahtany, YasirAlhammadi, Dean Kashiwagi, "Introducing a New Risk Management Model to the Saudi Arabian Construction Industry", Procedia Engineering, 940 - 947, 145 (2016).

[2] Alfredo Serpell, XimenaFerrada, Larissa Rubio, Sergio Arauzo, "Evaluating Risk Management Practices in Construction Organizations", Procedia - Social and Behavioral Sciences, 201 210, 194 (2015).

[3] LI Qing, LIU Rengkui, ZHANG Jun, SUN Quanxin, "Quality risk management model for railway construction projects", Procedia Engineering, 195 - 203, 84 (2014).

[4] Andreas Wibowo, JanuarTaufik, "Developing a Self-Assessment Model of Risk Management Maturity for Client Organizations of Public Construction Projects: Indonesian context", Procedia Engineering, 274 - 281, 171 (2017).
[5] Xiaohua Jin, Guomin Zhang, Junxiao Liu, YingbinFeng, JianZuo, "Major Participants in the Construction Industryand Their Approaches to Risks: a Theoretical Framework", Procedia Engineering, 314 - 320, 182 (2017).

[6] Pawelszymanski, "Risk Management in Construction Projects", Procedia Engineering, 174-182, 208 (2017).

[7] Adam Abderisak, GöranLindahl, "Take a chance on me? Construction client's perspectives on riskmanagement", Procedia Economics and Finance, 548 - 554, 21 (2015).

[8] Mohamed SayedBassiony Ahmed Abd El-Karim, Omar AlyMosa El Nawawy, Ahmed Mohamed Abdel-Alim, "Identification and assessment of risk factorsaffecting construction projects", HBRC Journal, 202-216, 13 (2017).

[9] AgnieszkaDziadosz, MariuszRejment, "Risk analysis in construction project - chosen methods", Procedia Engineering, 258 $-265,122$ (2015).

[10] Alfredo Federico Serpellaa,XimenaFerradaa, Rodolfo Howarda, Larissa Rubioa, "Risk management in construction projects: a knowledge-basedapproach", Procedia - Social and Behavioral Sciences ,653-662, 119 (2014) 